Cita bibliográfica: Íñiguez Ortega, P. (2017). Perspectivas actuales del contrato de gestión hotelera. Investigaciones Turísticas (14), pp. 164-183. http://dx.doi.org/10.14461/INTURI2017.14.09

\title{
Perspectivas actuales del contrato de gestión hotelera*
}

\section{Current perspectives of the hotel management agreement}

Pilar Íñiguez Ortega. Universidad de Alicante pilar.i@ua.es

\section{RESUMEN}

Resulta incuestionable en la actualidad, que el turismo constituye un complejo fenómeno con perfiles complejos y heterogéneos dentro del cual son abordados ámbitos muy diversos (económico, jurídico, político, cultural...). De forma inicial, dentro de la pluralidad de las relaciones que circunscriben el mismo, presentan especial transcendencia las conectadas, en mayor o menor grado, con la gestión y el alojamiento turístico. Lo que hace medio siglo resultaba inimaginable o, casi extravagante, constituye hoy una circunstancia común y frecuente en el escenario propuesto de forma particular, dentro del complejo y escasamente analizado ámbito de la gestión hotelera. Al hilo de lo expresado, en este trabajo se analizarápartiendo del supuesto de que la colaboración interempresarial en el sector turístico, puede sustentarse en capital o en relaciones contractuales- sus esenciales trazos conformadores sobre los cuales poder elaborar un concepto ordenado, como paso previo a la fijación de su régimen jurídico básico.

Palabras clave: contrato gestión hotelera, cadena hotelera, know-how.

\begin{abstract}
It is unquestionable that, today, Tourism is a complex phenomenon with heterogeneous profiles encompassing very different fields (economic, legal, political, cultural...). Initially, within the plurality of the relationships involved in the concept, those connected, to a greater or lesser extent, to tourism management and accommodation are particularly significant. What seemed unimaginable or even extravagant half a century ago is now a common and frequent circumstance in the proposed scenario, in particular, within the complex and scarcely analyzed field of hotel management. In line with the above, this study will analyse, assuming that the inter-business cooperation in the tourism sector can be based on capital or contractual relationships, the essential shaping factors (hotel manager and owner of the hotel managed) on which to develop an ordered concept as a preliminary step for establishing a basic legal system.
\end{abstract}

Key words: hotel management agreement, Hotel chain, know how.

*Contribución enmarcada en el Proyecto de investigación DER 2014-58765-R del Ministerio de Economía y Competitividad

Fecha de recepción: 8-07-2016

Fecha de aceptación: 22-05-2017 164

Este trabajo se publica bajo una licencia Creative Commons Attribution License Reconocimiento 4.0 


\section{PRELIMINAR. EL TURISMO: DUALIDAD PÚBLICO-PRIVADA DE LAS DISPOSICIONES CONSTITUTIVAS DEL DENOMINADO DERECHO DEL TURISMO: ESPECIAL REFERENCIA AL ALOJAMIENTO TURÍSTICO}

La evolución de los prototipos productivos y el avance hacia un modelo informacional en la gestión de todo tipo de conocimiento lleva consigo, tanto por su relevancia práctica como por su implicación socio-económica, un cuestionamiento permanente de la actual previsión normativa del denominado Derecho turístico.

En términos generales, la forma en que una determinada disciplina jurídica se configura sistemáticamente, no es una cuestión neutra por más que, en apariencia, obedezca a un designio ordenador, sin más pretensión que la de ofrecer una distribución racional de la materia concernida.

En la medida en que la opción sistemática agrupe, disperse, anteponga o relegue, necesariamente, debe introducirse un criterio material allá donde a simple vista, parece que sólo se trataría de resolver una cuestión formal. Por ello, si los elementos tomados en cuenta para fundamentar la opción o los aspectos afectados por ella, son complejos y variados, las consecuencias en la composición de la disciplina jurídica que corresponda, serán aún más relevantes, pues, en el fondo, terminarán condicionado su estructura y contenido.

Como es fácilmente intuible, el Derecho turístico en general, y más concretamente, el alojamiento turístico en particular, constituye un ejemplo significativo de tal aseveración, en la medida en que su ordenación sistemática, lejos de ser neutra, resulta inseparable de su delimitación material y de su diversidad tipológica. Así, el mismo se encuentra circunscrito tanto por reglas de carácter jurídico-privado como público.

En efecto, algunos autores, plateándose las diferentes tesis doctrinales sobre la eficacia -directa o indirecta- de la regulación administrativa, han abogado por la denominada administrativización del sector turístico, sobre todo, en el ámbito del indicado alojamiento turístico, favoreciéndose, según exponen, de un cuerpo de Derecho administrativo que ha pasado a ser lo que denominan derecho común de la empresa turística, concluyéndose, a tal efecto, que el derecho común de las relaciones hospederas no está constituido sólo por el derecho civil o cualquier otro de derecho privado, sino que contiene abundantes preceptos calificados como de Derecho administrativo (Martín Mateo et. al 1970, p. 2447).

Concebido de esta forma, el complejo entramado de dicha intervención administrativa sujeta a determinados principios de legalidad, igualdad, proporcionalidad, buena fe, confianza legítima e interés público, tiene como precedentes mediatos en el sector del turismo, el Plan Marco de Competitividad del Turismo Español (1992-1995)-conocido como Plan Futures I-; el Plan Marco de Competitividad del Turismo Español (1996-1999)conocido como Plan Futures II-; el Plan Estratégico de la Política Turística Española (20002016)-conocido como PICTE y el Plan Español Horizonte 2020 (2008-2011)- además del actual Plan Nacional e Integral de Turismo (2012-2016) (Pérez Guerra, 2014, p. 397).

A priori, en complemento a lo expuesto y teniéndose en consideración toda la evolución de la política turística, es necesario que se efectúe, al menos, como punto de partida- aunque sea de forma somera y sin entrar a valorar, pese a su importancia y dadas las características del presente trabajo, que ni permiten profundizar en los rasgos 
enunciados, en la incidencia de la supraterritorialidad, ni tampoco, en los presupuestos sobre el reparto competencial entre el Estado y las Comunidades Autónomas- que concretemos, al menos, la dualidad público-privada de las disposiciones constitutivas de lo que se ha venido a denominar, como previamente hemos anticipado, Derecho turístico.

A este respecto y con enlace en lo precedente, ha estado caracterizado en no pocas ocasiones, no sólo por su complejidad normativa, sino también, por una falta de rigor técnico a la hora de su elaboración y redacción, antes de pasar a analizar la específica relación contractual objeto del presente estudio, no sin antes recordar, como no puede ser de otra forma, que dicha dispersión normativa conlleva de manera generalizada, a una desigualdad legal de carácter territorial, la cual repercute, forma irremediable, sobre la seguridad jurídica del empresario turístico.

Bajo el planteamiento descrito, en opinión de Tudela Aranda, nuestra Constitución de 1978 (en delante CE)- la cual no modificó la configuración del poder discrecional de la Administración no aportándose, por ende, una legitimación que no tuviera inicialmente- fue la continuación de la tradicional mirada del legislador español sobre el turismo, casi de ajenidad, al considerarlo como un fenómeno esencialmente económico y sólo desde ese prisma, podría merecer la atención del poder público dentro del marco de un estado descentralizado (Tudela Aranda, 1996, p.17). Sobre ésta base, dicha Norma Fundamental prevé en su artículo 148, apartado 18, que las antes citadas Comunidades Autónomas podrán asumir competencias en la materia de "promoción y ordenación del turismo en su ámbito territorial" sin que el artículo 149 del citado Texto Legal, reserve para el Estado competencia directa sobre el turismo.

Partiéndose de esas consideraciones previas de orden general, el Tribunal Constitucional (entre otras, Sentencia 125/1984, de 20 de diciembre, 75/1989, de 25 de abril, y 88/1987, de 2 de junio) concluyó que el precepto antes reflejado no contenía una reserva competencial a favor del Estado sobre el turismo obviando a las antes nombradas Comunidades Autónomas, pero no olvidando que el mismo sigue siendo el órgano rector de la política turística estatal, de sus competencias así como de la ordenación y planificación del sector del turismo en cuanto parte integrante de la planificación de la actividad económica global.

Pues bien, es necesario recalcar que dichas Comunidades Autónomas, con sus propias legislaciones turísticas, han asumido la totalidad de las funciones y potestades públicas con carácter exclusivo sobre la materia indicada, no entrando en juego la cláusula residual del artículo 149.3 de la Constitución de 1978 -dado que los Estatutos de Autonomía de cada una de ellas, han sido cauce de asunción de las mentadas competencias sobre el turismo-. No obstante lo anterior, habría sido conveniente que en muchos supuestos, se hubieran tenido en consideración todos los Reales Decretos de Transferencias, lo que en definitiva, hubiera supuesto adentrarse de lleno y de manera más incisiva en el análisis específico de las competencias estatales en este sector, ex art. 149.1.13 CE).

Por otro lado, a pesar de su aparente claridad, no puede desconocerse la concurrencia en el sector turístico de otros títulos competenciales (recordando su palpable vaguedad redaccional) lo que justifica, en última instancia, la intervención del Estado en la promoción y comercialización del turismo español en el extranjero, las condiciones de obtención, expedición y homologación de los títulos profesionales del turismo, legislación en materia de agencia de viajes, seguro turístico, registros turísticos, defensa de consumidores 
o la coordinación general de la actividad turística..., sin que las mismas puedan interpretarse de manera expansiva, con el objeto de lograr vaciar las competencias autonómicas (Prados Prados 2008, p. 72 ). Lo deseable sería poder estructurar unos adecuados mecanismos de colaboración, convergencia y cooperación mediante una regulación ordenada, trascendente de coyunturas y con unos fines bien delimitados.

En consecuencia, tras esta síntesis sobre la dualidad en la ordenación jurídico-pública y jurídico-privada y desde la perspectiva de su evolución normativa, resulta difícil el poder establecer en este ámbito, una definición generalizada dentro del significado de lo que es denominado como alojamiento turístico y prestación de sus servicios, con el objeto de poder deslindarla de otras actividades relacionadas con dicho sector, confluyendo, como hemos tenido ocasión de anticipar con carácter previo, normas de muy diversa índole (estatales, sectoriales e incluso, europeas) lo que deviene que en última instancia, el sector turístico adquiera una dimensión interdisciplinar.

Continuando con la línea expositiva, son muchas las aportaciones doctrinales que evidencian unos puntos de conexión entre sus comunes. En efecto, Pérez Guerra y otro sector de la doctrina científica, definen como alojamientos turísticos aquellas empresas o establecimientos abiertos al público que facilitan de una forma habitual, específica y profesional, a cambio de un precio, el servicio de alojamiento, con o sin otros servicios complementarios, generalmente en relación directa de cantidad y calidad de los mismos a la clasificación del establecimiento y por motivos vacacionales y turísticos.

Asimismo, Ceballos Martín -que califica a esta versión como la mayoritaria en la doctrina- estima que son alojamientos turísticos aquellas empresas o establecimientos que facilitan de una forma habitual, específica y profesional en contraprestación a un precio, el servicio de habitaciones, con posibilidad o no de ampliar dicho servicio a la manutención, así como a otros complementarios a los anteriores, y generalmente en relación directa de calidad y cantidad de los mismos, siempre atendiendo a la clasificación de establecimiento (Pérez Guerra, 2006, p.18, Ceballos Martín 2002, p.74, Pérez Guerra et. al 1996, p. 99).

No obstante lo que antecede, se deberá tener en consideración la imprecisión técnica en que incurre nuestra Constitución de 1978 en más de una ocasión, cuando no, su decidida imprecisión del criterio de delimitación de la denominada mercantilidad en el ámbito del alojamiento turístico no sólo en su concepción, sino también, con relación a todos los contratos circunscritos al mismo (Gallego Sánchez, 2017, p. 42). Dicho lo cual, se ha propiciado que amplios sectores de materia técnicamente privada, se hallen mencionados en otros de sus apartados, lo que ha permitido a las Comunidades Autónomas legislar acerca de ellos o, al menos, ejecutar la normativa estatal.

Por lo demás, los criterios sentados por la jurisprudencia del Tribunal Constitucional que hemos recalcado con anterioridad distan, en muchas ocasiones, de ofrecer la firmeza y claridad que es exigible a un órgano jurisdiccional que debería decidir en atención a parámetros jurídicos, lo que ha dado lugar a no pocos conflictos y tensiones en este sector, impidiéndose en última instancia, el poder conseguir la deseable unidad de mercado amparada constitucionalmente y que los operadores económicos en general y aquellos otros relacionados con los alojamientos turísticos, en particular, demandan al romperse la coherencia interna exigible a todo sistema, provocando su ineficacia y generando gastos injustificados en este ámbito concreto. 
En función de ello y bajo las generales ideas anticipadas, un sector de la doctrina administrativista reseña como el contrato tipo de alojamiento turístico, pese a estar integrado en dichas disposiciones administrativas, es un contrato de empresa, por ende, mercantil, puesto que nadie se atrevería a calificarlo expresamente como un contrato administrativo. En efecto, lo que acontece cuando la Administración Pública interviene por vía reglamentaria en relaciones entre particulares, es que surgen junto a éstas-precisamente para asegurarlas en un determinado sentido-una serie paralela de relaciones entre los mismos, y evidentemente, entre la citada Administración junto al Derecho privado (Robles Álvarez de Sotomayor, 1981, p. 926).

Igualmente, otros autores mencionan la huida de las Administraciones Públicas hacia el Derecho privado, esto es, actuaciones de las mismas a través de personificaciones instrumentales que carecen de base territorial y sometidas a dicho sustrato normativo, en donde el indicado fenómeno tiene especial incidencia en el sector turístico, y en el cual, la actividad administrativa turística se ejerce a través de sociedades mercantiles sujetas al mismo. En cualquier caso, pese a que la reglamentación administrativa no incide jurídicamente en la validez o nulidad de un contrato, es difícilmente cuestionable su fuerza vinculante, sobre todo, en aquellos que celebren un contrato en el ámbito turístico (Blanquer Criado, 1998, p.55).

Adicionalmente, avanzando por la vía que antes apuntábamos, al objeto de poder satisfacer las necesidades que se suscitan en la práctica y respecto de las cuales los instrumentos que ofrece el ordenamiento jurídico en vigor resultan, a todas luces, insuficientes, nacen nuevas modalidades contractuales dentro del sector del alojamiento turístico y que denotan una notable fuerza expansiva, como el contrato de gestión hotelera, pero el cual carece, en última instancia, de una normativa reglada, lo que hace que se le denomine como relación contractual atípica o innominada, pero que, sin embargo, está dotado de una elevada tipicidad social derivada de su uso en el tráfico. Estas circunstancias ya anticipan los primeros inconvenientes a los que se enfrentan los operadores económicos en este ámbito del turismo (García Macho et. al, 2000, p.42)

A estos efectos, partiendo de un criterio objetivo que coloca al empresario y a su actividad -en su aspecto funcional y dinámico- en el origen del sistema que, de otro lado, no es ajeno por completo al Código de Comercio (en delante Ccom) y siendo numerosas las normas mercantiles funcionalmente conectadas a la idea de empresa turística en su concepción iusprivativista, como organización independiente, profesional, que tiene por objeto la distribución de bienes y servicios hacia el mercado, es contemplado, directa o expresamente, el fenómeno jurídico y económico que la circunscribe aludiendo también en sus aspectos conceptuales, a la actividad que desarrolla.

De otro lado, con sustento en las ideas que anteceden y centrándonos en la exacta configuración del contrato de gestión hotelera, calificaremos al mismo como contrato mercantil al darse la condición de empresario de, al menos, una de las partes -el gestor hotelero- y también por la índole de su objeto, el cual es el implícito desarrollo de una actividad de empresa, esto es, la prestación de servicios hoteleros de colaboración interempresarial en el sector del turismo.

Por consiguiente, nos detendremos a analizar sus principales trazos conformadores, las partes contractuales y sus genéricos derechos y obligaciones (tanto del gestor hotelero como del titular del establecimiento hotelero gestionado) sobre los cuales poder elaborar un 
concepto normativo ordenado y de subsunción del mismo en otros contratos afines, siendo éste un paso previo y necesario para la ulterior fijación de su régimen jurídico básico.

\section{ANTECEDENTES Y DELIMITACIÓN CONCEPTUAL. ELEMENTOS DE CARACTERIZACIÓN Y NATURALEZA JURÍDICA DEL CONTRATO DE GESTIÓN HOTELERA COMO FORMA DE GESTIÓN TURÍSTICA ACTUAL}

\subsection{Antecedentes y delimitación conceptual}

El avance de la industria turística insta a lo que hace medio siglo resultaba irrelevante, inimaginable o, casi extravagante, constituya actualmente una circunstancia común y frecuente en la actividad de la contratación hotelera.

Dentro de la pluralidad de las relaciones jurídicas establecidas que enmarcan el sector turístico, presentan especial transcendencia las conectadas, en mayor o menor medida, con la gestión y el alojamiento turístico (Pérez Moriones, 1998, p. 67, Montañer Montejano, 1998, p.3, Aurioles Martín, 2003, p.45).

Ahora bien, antes de examinar el despliegue normativo generado en torno a dicha relación contractual, con el objeto de poder analizar las relaciones jurídicas suscitadas entre las partes del contrato(gestor hotelero y titular del establecimiento hotelero gestionado), las cuales dimanan del management agreement o contrato de gestión hotelera- que como antes hemos recordado, es una forma de relación entre empresas y como vehículo de bienes y servicios lo que le convierte, sin duda alguna, en uno de los instrumentos jurídicos fundamentales y de mayor crecimiento utilizado actualmente por las cadenas hoteleras (Pérez Moriones, 1998, p.70)- es necesario efectuar una breve y selectiva panorámica a sus mediatos antecedentes no sólo nacionales, sino también, de Derecho comparado.

Como se acaba de poner de manifiesto, la primera evocación del contrato de gestión hotelera la encuadramos en el Derecho anglosajón del siglo XIX, particularmente, en las actividades ejecutadas en el sudeste asiático (concretamente, territorios coloniales) donde partiendo de la ausencia de profesionales capaces de una dirección eficaz de la actividad empresarial y de los importantes obstáculos a la obtención de créditos, surgieron las managing agencies como modo inicial de contrato de gestión de empresa.

Por otra parte, en Estados Unidos en la década de los años 20, se recurrió a los contratos de gestión empresarial en el ámbito del sector energético con el objeto de facilitar la transferencia de know-how a medio plazo (Iñiguez Ortega, 2015, p.31, Pérez Moriones 1998, p. 71), en donde los cuales, debido a la notable regularización de los servicios públicos, perdieron su virtualidad inicial y se manifestaron en otros ámbitos muy diferentes que se siguen utilizando en la actualidad (por ejemplo, asesoramiento de inversiones).

De ésta suerte, dicho modelo estructural fue seguido en Francia en donde el mandante eludía, pariendo de la antes citada estructura contractual, toda posible eventual responsabilidad generada por su actividad de gestión, siendo la misma traspasada, en mayor o medida, a una empresa gestora pero con un aprovechamiento evidente de los beneficios, 
esto es, una gérance-mandat en pequeñas y medianas empresas, difícilmente evacuable a la estructura actual de contrato objeto de estudio (Martín Miravalls 2008, p.4).

A mayor abundamiento, similares condiciones eran reflejadas en el Derecho sustantivo alemán, siendo utilizada dicha modalidad contractual para el desarrollo de la explotación de líneas de ferrocarril en países extranjeros, consistente en la creación de empresas mixtas y con una estructura societaria anónima, cuya dirección era asumida por otra empresa de gestión (Martínez Cañellas, 2014, p.834).

En nuestro país, la existencia de una disciplina aplicable a la prestación del servicio de alojamiento, no es exclusiva del presente siglo. En efecto, el sólido edifico de la actual reglamentación hotelera-que en muchas ocasiones, reflejó el Derecho comparado antes indicado y del que fueron claro exponente muchas Ordenes y Reales Decretos ya derogadosmarcaron la pauta para definir qué se entiende en la actualidad por empresas de hostelería en sentido propio, con especial incidencia en su actividad de gestión, aunándose diferentes modelos conceptuales de negocio, por ejemplo, los Paradores de Turismo de España, sustentados en unas características concretas de heterogeneidad, puesta en valor y diversidad que comenzaron su andadura en el año 1928 bajo el reinado de Alfonso XIII, en la denominada Comisaria Regia de Turismo y cuya primera normativa fue enmarcada en el Decreto 2245/1966 de 23 de julio, la Ley 16/1985 de 25 de junio, de Patrimonio histórico español y Real Decreto 11/1986, de 10 de enero que desarrolló, de forma parcial, la normativa anterior.

Bajo el escenario descrito, los mismos han realizado de la recuperación del patrimonio histórico-artístico sus señas de identidad; además, muchos de ellos se encuentran agrupados en la European Federation of Traditional Accomodation and Historic Houses, la cual venía de la mano de las antiguas Estancias de España y Hosterías-Hospederías Reales como una propuesta de turismo activo y cultural con el objeto de una promoción de negocio conjunta, esto es, la forma habitual o profesional de proporcionar habitación o residencia a las personas junto a otros servicios de carácter complementario y que enmarcaban los requisitos que debían exigirse -los cuales se siguen manteniendo hoy en día en la actual normativa-.

Sentado lo que antecede y de la mixtión de las históricas normas legales citadas teniendo presente el objeto central de nuestro estudio, que denotaría excesivo un análisis de todas y cada una de las disposiciones aplicables a los muy diferentes modelos de establecimientos hoteleros- podemos calificar y recalcar que el contrato de gestión hotelera objeto de análisis es atípico o innominado al no poder ser encuadrado dentro de las figuras regladas y articuladas por las leyes pero con una marcada implicación social, en donde el titular de un establecimiento hotelero confía su dirección y administración a un empresario, denominado gestor hotelero, que la lleva a cabo siempre en nombre y por cuenta del titular citado, integrando dicho establecimiento en una cadena o red de establecimientos similares, que también gestiona, además de identificarse con los signos distintivos de ésta a cambio de una retribución económica. 


\subsection{Elementos de caracterización y naturaleza jurídica del contrato de gestión hotelera como forma de gestión turística actual}

La función del contrato como vehículo jurídico al servicio de la circulación de bienes y servicios, le convierte en uno de los instrumentos jurídicos fundamentales y más antiguos del tráfico mercantil en sus diferentes ámbitos, siendo la más clara manifestación del principio de autonomía privada y de compromiso obligacional de las partes.

En este orden de ideas, las relaciones legales que enmarcan el contrato de gestión hotelera, son articuladas-sin perjuicio de posibles pactos accesorios $y / 0$ contratos coaligados- sobre una serie de obligaciones básicas y contrapuestas, así como sobre específicos deberes instrumentales en un contexto general de buena fe, lealtad y protección de recíprocos intereses.

En efecto, de forma general y encuadrada con la orientación procedente de nuestro Derecho de obligaciones -arts. 1254, 1258 y 1278 del Código Civil (en delante Cc) en relación con el art. 51 del Código de Comercio (signado Ccom)- lo calificaremos como un contrato consensual, atendiendo a los requisitos necesarios para su formación, esto es, perfeccionado por la mera concurrencia del consentimiento de las partes (tanto por parte del gestor hotelero como por parte del titular del establecimiento hotelero gestionado) que se produce por el concurso de la oferta y de la aceptación sobre la cosa y la causa del contrato (ex art. 1262 del (c), no exigiéndose con posterioridad, ningún otro requisito ulterior, lo que denota, a todas luces, una manifestación clara del principio espiritualista en la elección de la forma (art. 51 del Ccom) imperante en nuestro Derecho positivo, a menos que para determinadas relaciones contractuales especificadas en el citado Cuerpo Legal o en las Leyes especiales, se requieran formas o solemnidades necesarias para su eficacia (ex art. 52 del Ccom), cuestión que no acontece en el contrato objeto de nuestro análisis.

De igual modo, lo caracterizaremos como bilateral o sinalagmático, al surgir obligaciones específicas para ambas partes contractuales de tracto sucesivo, pues su duración ordinaria, a tenor de la práctica mercantil en el ámbito hotelero, oscila entre diez y quince años prorrogables, y oneroso, respondiendo a la circunstancia de que cada una de las partes que intervienen en dicha relación contractual busca obtener una ventaja económica o una contraprestación implícita.

No obstante, continuando con las ideas que anteceden y en aras a una adecuada caracterización, parece evidente la aplicación de manera analógica y de forma extensiva al contrato de gestión hotelera, lo prevenido en el art. 2.2 del Ccom (que postula un principio de objetivación en este tipo contractual), el cual recalca la consideración como actos de comercio, aquellos realizados por comerciantes en su tráfico, y también, por los que se organizan como ellos, que no son otros, tal y como acontece en el análisis de la figura objeto del presente trabajo, que los empresarios turísticos. En la misma línea, siguiendo el iter literal del precepto, se establece: “...cualesquiera otros de naturaleza análoga” -refiriéndose, esencialmente, a cualquier otro contrato coaligado con el anterior que surja del tráfico empresarial dentro del marco de la actividad de empresa-. 
Asimismo, efectuando un reconocimiento implícito de la no resuelta discusión legal entre la noción de gestión o administración de intereses ajenos, se entiende que la misma, siempre dentro del ámbito que nos compete, no sólo debe abordar actos jurídicos concretos, sino cualesquiera otras actividades materiales que, por sí solas, no exigen el despliegue de actos de carácter económico o de aquellos otros que presenten un interés exclusivamente personal (Peinado García, 1996. p.38).

Por todo, en atención a los elementos caracterizadores y a las manifestaciones precedentes, su disciplina jurídica habrá de integrarse no sólo por las normas generales sobre contratación con las especialidades propias mercantiles, sino también, atendiendo a la normativa de los tipos más próximos como es el contrato de comisión (ex art. 244 del Ccom en relación con el art. 1709 del $(\mathrm{C})$ ), puesto que es estipulado un negocio jurídico -acto u operación de comercio por parte del gestor hotelero en su condición de empresario mercantil- de prestación de su actividad, la cual consiste en la gestión del establecimiento hotelero por cuenta su titular, aceptando y ejecutando los encargos encomendados (Iñiguez Ortega, 2015, p. 52).

No obstante lo anterior, otro sector doctrinal ha abogado-y siempre recordando que se trata de una cuestión no pacífica también jurisprudencialmente (véase al efecto, la Sentencia del Tribunal Supremo de 28 de enero de 2002)- por la aplicación extensiva de la normativa de la Ley 12/1992, de 27 de mayo del Contrato de Agencia (Lázaro Sánchez, 1989, p.126, Martínez Sanz, 1996, p.25, Martínez Cañellas, 2014 p.850), lo que conllevaría el mantenimiento de la naturaleza imperativa de aquellas cuando son aplicables al contrato a estudio. Es evidente que todo ello nos llevaría a analizar una cuestión jurídica que excede del objeto de nuestro trabajo pero con una notable trascendencia práctica, porque de ella dependerían, en última instancia, la validez de las cláusulas contenidas en los contratos de gestión empresarial, cuya redacción pudiera constituir una exclusión o limitación del contenido de las disposiciones que contiene el referido Cuerpo Legal.

De igual modo, en complemento a lo anterior, también le pueden ser aplicadas las normas de nuestro Ccom sobre la figura del factor mercantil. Ahora bien, no hay que olvidar que las directrices marcadas por el titular del establecimiento hotelero gestionado- que como hemos mencionado, deberá entregar un poder lo suficientemente amplio para permitirle ejercitar todos los actos de gestión ordinaria del hotel, tanto desde un punto de vista jurídico como de hecho (arts. 281, 292 y 293 del Ccom)-no incluyen los específicos actos de disposición (salvo los suministros de bebida y comida), gravamen o endeudamiento.

La coherencia de esta construcción jurídica aplicable al contrato objeto de análisis, parece quebrar en la disciplina relativa a la revocación del poder (ex arts. 279, 290 y 291 del Ccom). El poder debe ser irrevocable, pues no sólo el titular del establecimiento hotelero gestionado, sino la cadena hotelera gestora, tienen un interés directo en el ejercicio del mismo. Ahora bien, dicha irrevocabilidad se deberá pactar expresamente en el clausulado contractual, dado que la regla positiva general deviene en sentido contrario, esto es, la revocabilidad del mismo (art. 279 Ccom antes citado).

Finalmente, no hay que olvidar, siguiendo la regla general de la representación (de la que no puede extralimitarse, puesto que nos introduciríamos de lleno en la doctrina científica del falsus procuratur, generando responsabilidad por daños y perjuicios, salvo ratificación posterior, ex arts. 1279 y 1727 del citado Texto normativo), la existencia de 
vinculación del gestor hotelero a los contratos celebrados con terceros, pues si actúa en nombre propio y sin indicar por cuenta de quien efectúa dicha gestión, se generará responsabilidad directa sobre los contratos firmados por él y los indicados terceros no tendrán poder de actuación, en ningún supuesto, contra el titular del hotel gestionado.

\section{DERECHOS $Y$ OBLIGACIONES DEL GESTOR HOTELERO $Y$ DEL TITULAR DEL ESTABLECIMIENTO HOTELERO GESTIONADO, DERIVADAS DE LA RELACIÓN JURÍDICO-CONTRACTUAL}

\subsection{Obligaciones principales}

En este contexto, diferenciaremos las obligaciones asumidas por parte del gestor hotelero para con posterioridad, analizar todas aquellas previstas para el titular del establecimiento hotelero que se gestiona.

Conforme a ello, partimos de la genérica obligación de administración por parte de la cadena hotelera gestora (esto es, dirección y explotación del establecimiento) la cual será siempre llevada a cabo por la primera en interés del gestionado, que como es fácilmente constatable, destaca por su amplitud de contornos. Merced a lo anterior, no sólo por la índole de la obligación que asume sino, sobre todo, por la condición de gestor de intereses ajenos, le es impuesta otra serie de deberes específicos cuyo fundamento se encuentra en analogía con el resto de relaciones en que se advierte esta misma característica y de los que hemos efectuado referencia en apartados precedentes.

En efecto, comprende todas aquellas operaciones que sean necesarias o convenientes para el desarrollo de tal prestación, con independencia de la naturaleza jurídica, material o intelectual de las mismas, esto es, la dirección técnica del personal del hotel en las actividades necesarias para la prestación de servicios propios de un establecimiento de hostelería; obras y labores de reformas que se tengan que acometer en el establecimiento; de mantenimiento; de contratación de todos los servicios y suministros necesarios ... (Iñiguez Ortega, 2015, p.90).

En esta misma línea expositiva, se incluirá toda la organización y gestión económicocontable de las operaciones que impliquen la explotación del establecimiento hotelero de manera puntual y periódica (art. 263 Ccom en relación, por aplicación analógica, con el art. 10.3 de la Ley del Contrato de Agencia; véase Martínez Cañellas, 2014, p.854), así como cualesquiera actividades de promoción y publicidad efectuadas por el gestor hotelero (ex arts. 8 a 22 de la Ley General de Publicidad de 1988, recordando que la misma ha sufrido cambios en la numeración a raíz de la Ley 29/2009, de 30 de diciembre, por la que se modifica el régimen legal de la Competencia Desleal y Publicidad para la mejora de los consumidores y usuarios, con el objeto de una mayor proyección, tanto nacional como internacional del mismo, así como el planteamiento y la adopción de estrategias de empresa que puedan conducir a una mejora general de su rendimiento).

De esta forma, dichas obligaciones la podemos calificar como de resultado, máxime cuando se percibe una remuneración condicionada al cumplimento de las condiciones contractuales. En cualquier caso, aun considerando que se tratara de una obligación de 
medios, el incumplimiento de los objetivos fijados en el contrato permitiría establecer una presunción de culpa por parte del gestor hotelero. A tales efectos, para su concreta comprobación, se invertiría la carga de la prueba correspondiendo a la cadena hotelera gestora probar que su actividad es la adecuada a un ordenado empresario, la cual no sólo se reflejaría en un comportamiento activo, sino también, en el deber de facilitar al titular del establecimiento gestionado toda la información recogida, valorada, analizada y filtrada que pudiera serle útil en el ejercicio de su actividad empresarial.

No obstante lo que antecede, bajo ningún supuesto las instrucciones recibidas al efecto deberían sobrepasar los límites establecidos por el titular del establecimiento hotelero, puesto que en todo aquello que se exceda, se quedarían con cargo del propio gestor hotelero salvo que, posteriormente, fueran ratificadas por la otra parte (art. 1715 y 1727 Cc). Por tanto, cualquier anomalía en estas prescripciones legales, aun reconociendo la tendencia específica hacia la objetivación que recoge nuestro Derecho mercantil, generará responsabilidad por los daños y perjuicios causados por dicha conducta irregular (arts 254 y 267.1 (com).

Ahora bien, nos planteamos, que sucede cuando la cadena hotelera gestora no ha recibido reglas delimitadoras precisas, aunque del contrato de gestión puedan llegar a deducirse de forma implícita (falta o insuficiencia de instrucciones, inadecuación, ambigüedad, contradicción...) o, en su caso, no fuera posible una comunicación con el titular del establecimiento en un momento determinado (inexistencia de medios). Evidentemente, conlleva el riesgo de que los objetivos perseguidos por la celebración del contrato de gestión hotelera, no sean satisfechos.

Esta cuestión es resuelta en el Ccom en sede del contrato de comisión (arts. 255 y 254 del referido Cuero Legal) declarando la necesidad de reestablecer por la forma más rápida posible, la comunicación entre el comisionista y el comitente, solución perfectamente aplicable al contrato de gestión hotelera, puesto que las obligaciones del comisionista son, en esencia, la mismas que competen al mandatario como gestor de intereses ajenos, esto es, ejecutar el negocio de realización (Gallego Sánchez, 2015, p.291). Sobre este particular, si la consulta no fuera posible, hará lo que le dicte la prudencia y sea más conforme al uso de comercio, cuidando el negocio como si fuera suyo (arts 255.2 y 258 del Ccom.).

Todo ello, inexorablemente, deberá ir acompañado del deber de diligencia implícito a todo ordenado empresario y de lealtad -sustentado en la buena fe objetiva, ex art. 1258 Cciv.- por parte del gestor hotelero frente a la contraparte, sometiéndose a las instrucciones del titular del establecimiento gestionado como actos de especificación del encargo recibido, las cuales atenderán, en última instancia, a las necesidades y circunstancias de dicho negocio hotelero, siempre guiándose bajo parámetros de razonabilidad y persiguiendo los intereses del titular por encima de los propios prohibiéndoles la obtención de ventajas a costa del primero.

Por otra parte, dichos deberes deberán estar anudados al amplio deber genérico de información, establecido en todos los negocios de gestión de intereses ajenos, debiendo comunicar al titular del establecimiento gestionado cualquier circunstancia propia de su obligación gestora, lo que le impedirá siempre utilizar en beneficio propio y/o ajenos, secretos industriales (o know how) a los que haya tenido acceso en razón de la relación contractual especificada. 
Continuando con el hilo expositivo, deberá además y derivado de las necesidades de organización interna de la actividad empresarial, llevar una contabilidad ordenada y adecuada a dicha actividad de gestión hotelera, que permita un seguimiento cronológico de las operaciones mercantiles efectuadas, así como la elaboración periódica de balances e inventarios (ex art. 25.1 Ccom). En efecto, todo ello permitirá conocer con claridad la imagen fiel de su patrimonio, su situación financiera, así como los resultados obtenidos, tan necesarios para la gestión del establecimiento hotelero (art. 34.2 del Texto Legal citado y Resolución de la Dirección General de Registros y Notariado, de 16 de febrero de 2000 complementado por el Plan General de Contabilidad aprobado por RD 1514/2007, de 16 de noviembre y la Ley 26/2007, de 4 de julio, de reforma y adaptación de la legislación mercantil en materia contable para su armonización internacional con base en la normativa de la Unión Europea, ajustándose a las Normas Internacionales de Información Financiera (NIIF) contenidas en el Reglamento 1606/2002, del Parlamento Europeo y del Consejo, de 19 de julio de 2002). Esta obligación constituye la diferencia esencial entre el contrato de gestión hotelera y la franquicia hotelera pues, en el primero, quien gestiona es el gestor hotelero, mientras que en la franquicia, lo hace el propietario del establecimiento hotelero, quien será por tanto, el que en última instancia, retenga el riesgo de la explotación del negocio.

En segundo término, procede abordar el análisis de las obligaciones que surgen para el titular del establecimiento hotelero gestionado, siendo tradicionalmente integradas en la denominada actio negotiorum gestorum contraria.

En este punto, además de ciertas actividades de carácter preparatorio -que pueden llegar a implicar modificaciones en la construcción o decoración de los distintos departamentos al objeto de integración en su red hotelera, las cuales serán especificadas en un "Anexo" del contrato de gestión- el titular del establecimiento hotelero gestionado aludido, deberá entregar el inmueble como una unidad productiva susceptible de funcionamiento inmediato, junto con la maquinaria, mobiliario, útiles y enseres, con los trabajadores, licencias, concesiones y autorizaciones necesarias al efecto.

En un lugar común con lo expuesto, se deberán igualmente, reembolsar en la forma y cuantía pactada, cualquier gasto de gestión generado por la cadena hotelera, así como el abono de la remuneración pactada (art. 277 Ccom) en una cantidad fija o variable, recordando que no existe en el contrato objeto de estudio, referencia alguna de imposición concreta al gestor hotelero con el objeto de no coartar su libertad de actuación, ni tampoco refiere ningún impedimento en su asunción, al igual que acontece en otros tipos contractuales afines y que hemos tenido ocasión de indicar en el apartado precedente, como la comisión (art. 1709 Cc, art. 244 a 262 del Ccom), siempre que sean respetadas las pautas delimitadas por ambas partes en el clausulado contractual y llegue a buen fin el resultado perseguido inicialmente. Por tanto, asume en exclusiva la responsabilidad frente a terceros.

De la afirmaciones anteriores se deriva, con el mismo tenor, que deberán sufragarse aquellos daños y perjuicios que hayan podido ocasionarse a la cadena hotelera gestora, al ser la consecuencia necesaria del hecho de que ésta actúa en interés y por cuenta del gestionado (siempre, claro está, que se alegue y pruebe su importe, ex arts. 278 y 253 del 
Ccom), así como de los intereses legales generados para el supuesto de retaso en su abono por parte del titular del establecimiento hotelero (arts. 277 y 278 del Cuerpo Legal citado en relación con la Ley 3/2004, de Morosidad de Operaciones Comerciales, modificada por Ley 15/2010, de 5 de julio y por el Real Decreto-ley 4/2013, de 22 de febrero, de medidas de apoyo al emprendedor y de estímulo del crecimiento y de la creación de empleo).

\subsection{Obligaciones accesorias}

Unido a todo lo anterior, tal y como se deriva de la praxis mercantil, junto a todas las obligaciones preparatorias y principales analizadas, el gestor hotelero deberá cumplir con el ineludible deber de rendición de cuentas al titular del establecimiento hotelero (arts. 34.1, 35.1 y 36.1 del Ccom), la cual abarcará de forma amplia, cualquier actividad delegada por parte del titular del establecimiento hotelero al gestor, trasladándole el resultado y los efectos obtenidos del encargo de gestión ejecutado.

En este orden de ideas, ésta última obligación no se integra por una comunicación meramente declarativa o descriptiva, sino fundamentada y justificada que deberá ser modulada en función de la naturaleza del encargo recibido (Broseta Pont, M. y Martínez Sanz, 2015, p. 117). De hecho, la misma podría proceder de diferentes fuentes, presentando una serie de aspectos cuantitativos y cualitativos a través de los cuales se podrá determinar objetivamente el resultado económico de la gestión sobre el establecimiento hotelero gestionado $y$, en último término, servir de sustento para la exigencia de una posible responsabilidad.

Por tanto, de las observaciones anteriores se infiere que el gestor hotelero presentará una declaración pormenorizada, que será acompañada de los oportunos justificantes que permitan la comprobación de la realidad plasmada, debiéndose con posterioridad ser aprobadas por el titular del establecimiento que se gestiona, a tenor de lo establecido en los arts. 263 del Ccom y 1728 del Cciv.

Continuando con el hilo expositivo y en punto a las obligaciones accesorias que surgen para el titular del establecimiento hotelero, en primer lugar, será el abono de todos los gastos derivados consecuencia de la ejecución de su administración (similar a los que establece el art. 278 del Ccom en relación con los gastos generados con ocasión de la ejecución del contrato de comisión), esto es, facturas, royalties, revisiones, staff fees ...los cuales deberán necesariamente reflejarse en el clausulado del contrato). Asimismo, en complemento a lo que antecede, se determinará contractualmente si, en última instancia, asumirá todos aquellos gastos derivados de la formación del personal. Ahora bien, las consecuencias generadas de las actuaciones culposas por parte del gestor hotelero en la ejecución de sus obligaciones contractuales, quedarán exentas de abono por parte del gestionado.

Llegados a este punto, deberá satisfacer, no sólo con la finalidad de mejor regulación de las relaciones jurídico-privadas que unen a ambas partes contractuales, sino también, con referencia a su protección y para el supuesto de la posibilidad de existencia de riesgos, la contratación de diferentes modalidades de seguros, esto es, incendios (art. 45-49 Ley de Contrato de Seguro (en adelante LCS), de robo (art. 50 LCS), de terremotos, (en este caso, corresponderá su indemnización al Consorcio de Compensación de Seguros), de inundaciones, que puedan destruir total o parcialmente el hotel (art. 1, 8.4 LCS y art. 76 del 
citado Texto legal en relación con el art. 38.6 LCS en aplicación de la Ley 15/2015, de Jurisdicción Voluntaria o por la legislación notarial); seguros de responsabilidad civil (arts. 73-76 LCS) los cuales, amparados por el principio de especialidad del riesgo, tienden a cubrir el riesgo de que el patrimonio del asegurado se vea gravado por la obligación de reparar daños causados a terceros, por un hecho del que sea civilmente responsable (arts. 73-76 LCS); seguros de crédito y caución (arts. 70-72 LCS) y de reaseguro- cut-thorough clauses(arts. 77 y 78.1 del referido Cuerpo Normativo), seguros de accidente (art. 81 LCS).

A estos efectos también serán incluidos los seguros por interrupción del negocio (el denominado lucro cesante) mediante el cual, es asegurada la pérdida de beneficios y los gastos generales que haya de seguir soportando el titular del establecimiento gestionado, para el eventual supuesto de paralización total o parcial de la empresa (arts. 63-66 del anterior Texto normativo). Por ello, dicha indemnización vendrá determinada en la póliza pero, en defecto de pacto expreso, deberá comprender tanto la pérdida de beneficios como los gastos generales del establecimiento hotelero; además de los seguros de crédito y caución (art. 68-72 LCS), y lógicamente, de los seguros de las personas que trabajan en dicho establecimiento hotelero, como seguros de previsión que son (art. 80 a 106 quarter LCS).

Finalmente, deberá entregar al gestor hotelero todas las certificaciones de las pólizas de dichos seguros en el periodo de vigencia correspondiente, es decir, unas incardinadas al periodo de construcción del inmueble y su inicial equipamiento y otras, a partir de la fecha de apertura del mismo (Iñiguez Ortega, 2015, p.131, Pérez Moriones, 1998, p. 305).

\section{EXTINCIÓN DEL CONTRATO DE GESTIÓN HOTELERA}

Con carácter inicial, aun refiriéndonos a la función de equilibrio de intereses que debe de cubrir todos los discursos en torno al eventual régimen jurídico de aplicación a cualquier fenómeno atípico, quedan por analizar en el presente trabajo, las consecuencias que dimanan al finalizar la relación contractual que une a ambas partes así como, en su caso, la procedencia de compensar económicamente al gestor hotelero por su gestión de intereses ajenos.

En este punto, además de por las concretas causas generales y ordinarias de extinción contractual ( cumplimiento del término, realización del negocio...), se encuentran las anudadas al contrato de gestión hotelera (cuyo fundamento genérico se encuentra en la caracterización del convenio como una relación de confianza), a las que clasificaremos en orden a la intervención o no, de una declaración de voluntad, estimándose su importancia en función de la conflictividad reflejada ante los órganos jurisdiccionales, esto es, un primer grupo, que englobaría aquellas cuya operatividad dependería directamente de la voluntad de una de las partes (el desistimiento ad nutum), y un segundo grupo, donde se enmarcarían aquellas sustentadas en el acaecimiento de circunstancias objetivas, que generarían, en la mayoría de los supuestos, el inicio prácticamente de forma automática, de todo el procedimiento extintivo del contrato.

Pues bien, en primer lugar y con relación al cumplimiento del plazo pactado en el contrato, éste se extingue al llegar el término establecido y reflejado en su clausulado (véase la Sentencia del Tribunal Supremo, Sala primera, de 27 de marzo de 2008 por su claridad expositiva), teniendo en consideración que son relaciones jurídicas contractuales con una 
larga duración en el tiempo (de 10 a 15 años), sobre todo porque la integración de un hotel en una cadena hotelera con implantación mundial puede tardar unos cinco años, hasta que se encuentre en plena producción (Martínez Cañellas 2014 p.836), no existiendo la obligatoriedad de un plazo de preaviso, ni tampoco de notificación alguna al respecto por cualquiera de las partes intervinientes.

Por lo demás, si la cadena hotelera gestora y el titular del establecimiento gestionado siguen ejecutando dicha relación jurídico-contractual después de finalizado el plazo de duración inicial, ha de entenderse que el contrato de gestión hotelera se transforma en contrato de duración indefinida. Asimismo, es viable la inclusión en el contrato un derecho de adquisición preferente al final del periodo establecido por ambas partes en la gestión encomendada a favor del gestor hotelero, la cual deberá ser comunicada de forma fehaciente, al titular del establecimiento hotelero gestionado.

Bajo estos presupuestos, se desprende que la extinción, per se, del contrato en el caso aludido, no genera derecho de indemnización en favor de ninguna de las partes, puesto que rige el acuerdo inicial fijado al comienzo de su relación jurídica. Cuestión diferente es la producción de una prórroga contractual, que se podría ser aplicable mediante una revisión del clausulado contractual al no entender posible la tácita reconducción propia del contrato de arrendamiento, según la cual, de no existir preaviso, se entendería prorrogado 15 días, lo que resultaría claramente inadecuado en contrato de gestión hotelera.

Continuado el hilo expositivo, otra causa anudada a la extinción contractual, es el desistimiento unilateral como acto jurídico de declaración de voluntad, el cual, siendo una figura que aun a pesar de carecer de una regulación específica, no resulta desconocida para nuestros Textos normativos, recordándose a tal efecto, que en el sector hotelero no responde a un concepto unitario y se admite bajo determinadas condiciones. En efecto, hay manifestaciones que han sido objeto de plúrimas definiciones por parte de la doctrina, habida cuenta de la diversidad de hipótesis sostenidas sobre su origen. Así pues, es un reconocimiento interpartes de la esencial facultad liberatoria que asiste a todo contratante, el cual podría verse sometido a una vinculación potencialmente perpetua (Iñiguez Ortega, 2015, p. 144).

Por otro lado, es posible que, en muchas ocasiones, el titular del establecimiento hotelero que se gestiona, quiera efectuar una reducción de sus costes y las cadenas hoteleras gestoras quieran mantener su nivel de ingresos además de la calidad de su marca. Pues bien, aun a pesar de que dicha revocación se estimaría libérrima por presuponer el contrato una relación de confianza, finalizaría por su simple voluntad, sin necesidad de justificar causa alguna. Así se expresa el art. 279 del Ccom, que no parece supeditar tal facultad al carácter indefinido del contrato, único supuesto donde se admitiría tal posibilidad en la doctrina general de contratos (Gallego Sánchez, 2017, p. 135)

Se trataría, por tanto, de una hipótesis extraña al tracto instantáneo que caracteriza a este tipo de convenios. En este sentido, el Tribunal Supremo (Sentencia de 9 de septiembre de 2000) ha admitido la posibilidad de libre revocación a pesar de la existencia de plazo, supeditándola, en última instancia, a la necesidad de una indemnización de daños y perjuicios sufridos. Si bien, no es ocioso recordar en este apartado, que no existe en nuestros órganos jurisdiccionales una línea clara de diferenciación entre el contrato de gestión hotelera objeto de debate con aquellas otras relaciones contractuales con las que 
presentan similitudes. En orden a ello, se debe asumir necesariamente a estos efectos, la tesis de la recepción o conocimiento del destinatario de dicha revocación, la cual deberá ser asumida por la contraparte, esto es, por el titular del establecimiento gestionado (art. 279 Ccom).

Al contrario, no finaliza el contrato de gestión hotelera por renuncia del gestor. Así, los motivos se anudan, en primer lugar, a la incompatibilidad de su admisión con las conveniencias del tráfico mercantil, puesto que la gestión encomendada se integra dentro del giro de la actividad empresarial del titular del establecimiento hotelero, respecto del cual puede constituir la base de otras; y en segundo término, al carácter profesional del gestor (art. 252 del Ccom que le impone la responsabilidad por daños si no cumple con la gestión aceptada frente a los establecidos en el art. 1732 del Cc). Incardinado a ello y junto al tenor literal de los preceptos referenciados, suele incluirse, asimismo, la extinción de los contratos de cupo o contingente celebrados en el desarrollo de la actividad empresarial por el gestor hotelero con las agencias de viaje que son colaboradoras del mismo.

Otra circunstancia a tener en consideración, sería el incumplimiento resolutorio, tanto por causa o motivo grave en cualquiera de las partes del contrato, que implicaría una imposibilidad de ejecución y posible desviación de los objetivos de rentabilidad empresarial derivados de su gestión. Es evidente que la misma no se encuentra delimitada, al menos, como supuesto de hecho, para el incumplimiento que objetivamente admite la ejecución in natura posterior. A tal efecto, la doctrina científica aboga por dos criterios específicos para delimitar si el incumplimiento es grave: en primer término, la concepción subjetiva, la cual se centra en las consecuencias específicas generadas para el titular del establecimiento hotelero, y en segundo lugar, la concepción objetiva que atiende principalmente al resultado global del incumplimiento en la relación jurídico contractual así considerada.

Como es fácilmente deducible en este apartado, estimamos que sería necesario diferenciar entre el mero retraso y el incumplimiento en la relación contractual, considerándose que el primero, cuando no va enlazado a cualesquiera otras circunstancias que deriven hacia la conclusión del contrato de gestión hotelera, no autoriza, per se, a su resolución. Todo ello implicaría una valoración previa sobre la trascendencia del mencionado retraso en la realización de cualquier actividad de gestión, entendiendo que sólo aquellas calificables como graves, deberían tener efectos resolutorios.

En nuestra opinión, la prestación parcial o defectuosa, no excluye fehacientemente el incumplimiento, puesto que es necesario valorar la gravedad o la incidencia del mismo sobre la economía del contrato. El Tribunal Supremo (véase, entre otras, la Sentencia de 17 de febrero de 1998) ha estimado que el remedio resolutorio contractual no sólo cabe en aquellos supuestos en los que no existen propiamente defectos de prestación, sino una prestación inútil o inservible para su uso si no es posible la eliminación posterior del vicio, puesto que se estima que son comportamientos descorrectos que hacen, permítannos la expresión, "venir a menos" la relación fiduciaria por una trascendente pérdida de confianza en la contraparte (que como hemos expuesto en el presente estudio, es esencial para este tipo de contratos) o de cualesquiera otras circunstancias o hechos sobrevenidos determinantes de la inviabilidad de la relación entre el gestor hotelero y el titular del establecimiento gestionado, por afectación implícita a los intereses contractuales. 
Bajo este prisma expositivo, nos preguntamos si el gestor hotelero también se obliga contractualmente a la adquisición de determinadas materias primas debiendo, en muchas ocasiones, mantener un concreto porcentaje de stock de recambio y de suministro que facilite las labores de gestión del hotel. Tal situación que a priori aparece como beneficiosa para todos los sujetos implicados en la relación contractual, se torna peligrosa al abordar su finalización.

Piénsese que la utilización de los signos distintivos del gestor hotelero por parte del titular del establecimiento hotelero gestionado, está ligada a la supervivencia del contrato y a la integración en una red hotelera concreta y de prestigio, en muchos supuestos, de ámbito internacional (a modo ejemplificativo, la integración citada puede ser desde muy diferentes ámbitos: establecimientos hoteleros que pertenecen a cadenas hoteleras horizontales, establecimientos hoteleros integrados en una franquicio hotelera, una marca hotelera con diferentes propuestas de valor...).

En cualquier caso, a la extinción contractual, el titular del establecimiento hotelero-y así se habrá establecido en su clausulado-dejará de utilizar todos los signos distintivos de estilo del gestor del hotel con el objeto de evitar confusión pública respecto a la fuente o a la calidad de los mismos, lo que derivaría, en supuestos de incumplimiento, poder llegar a constituir infracciones de la normativa de marcas además de poder ejercitarse, en su caso, las acciones recogidas en la Ley marcaria por violación y lesión de derechos ante los órganos jurisdiccionales (arts. 40 a 45 de la Ley 17 /2001, de 7 de diciembre, de Marcas).

En otro orden de ideas, la fuerza de la distinción y el valor de los derechos puede haberse incrementado a través de su utilización en la gestión del hotel pero, evidentemente, sólo puede beneficiar a su titular marcario en la medida en que aquél únicamente ha gozado de un derecho de uso limitado en el tiempo que ahora, por efecto de la cesación de la relación contractual por las diferentes causas que hemos indicado, ha procedido a su fin.

No obstante lo anterior, con base en el principio de la buena fe objetiva en la ejecución de estos especiales contratos, parecería justo permitir al gestor hotelero la posibilidad de liquidación de las existencias de productos identificados con su marca de prestigio empresarial. A tal efecto, sería conveniente la inclusión en el contrato que liga a ambas partes, una opción u obligación de compra, ponderándose circunstancias diversas, por ejemplo, si dichas adquisiciones se realizaron como consecuencia de cláusulas de cuota o de mínimos.

Con esa premisa, también se abogará por aplicar las normas generales de las obligaciones y contratos, estimando que podría llegar a hablarse de un derecho de restitución en los supuestos específicos de condición resolutoria, anulación, nulidad contractual, y también, en los casos de incumplimiento con sustento en la imputación de perjuicio personalizado. Fuera de ello, nos encontraríamos con un determinado riesgo contractual que debería ser asumido, salvo pacto en contrario, por la cadena hotelera gestora.

Finalmente, se puede extinguir la relación jurídico-contractual por fallecimiento o inhabilitación del gestor hotelero (ex art. 280 del (com) e, incluso, aunque el referido Texto normativo no lo mencione expresamente, por disolución y subsiguiente extinción de la sociedad gestora (cadena hotelera) como supuesto equiparable al fallecimiento de la 
persona física. Sin embargo, sí será extinguida dicha relación contractual por muerte o inhabilitación del titular del establecimiento hotelero, en contra de lo prevenido en el art. 1732.3 del Cciv, en tanto cuentan aquí las necesidades derivadas del tráfico empresarial en relación con la seguridad jurídica y con la protección de terceros. No obstante lo anterior, tanto sus herederos como sus representantes pueden revocarlas en las condiciones establecidas en el los precepto legales citados.

\section{CONCLUSIONES}

Durante muchos años, el coste de mantener la propiedad de los establecimientos hoteleros era, permítannos la expresión, una losa demasiado pesada que restaba agilidad al tráfico económico, por lo que la solución pasaba, bien por un sacrificio excesivo en su ansia de crecimiento y expansión, o bien, se optaba por implantar y hacer suyo el ejemplo de las grandes cadenas internacionales, defensoras de reducir el riesgo y de la gestión mediante una nueva estructura contractual, el management agreement, el cual se ha ido implantando de forma sustancial, en nuestro país, a lo largo de los últimos años de la mano de los grandes operadores turísticos, como alternativa real y efectiva a los arrendamientos fijos hoteleros.

Hemos analizado a lo largo del presente trabajo, la notable complejidad del contrato de gestión hotelera, desde un punto de vista jurídico, al confluir en su configuración normativa de diferentes ámbitos (público-privado), así como también, diversas leyes especiales.

La necesaria reformulación de la materia mercantil y codificación integradora de la legislación especial influida por el Derecho comparado, particularmente en el ámbito contractual, efectuada por el Anteproyecto de Ley de Código Mercantil de 30 de mayo de 2014-para el supuesto de aprobación final- que sustituirá al Código de Comercio de 1885, era necesaria, pero no queremos desaprovechar la ocasión para criticar profundamente, las significativas diferencias con relación a la Propuesta de Código elaborada por la Comisión de Codificación y presentado el 17 de junio de 2013, texto de sólida base académica, en el que participaron durante casi 13 años, insignes juristas.

Pues bien, partiendo de la anterior premisa, aun a pesar del nuevo contexto en el que habrá de desenvolverse la Codificación mercantil y del Dictamen del Consejo de Estado de 29 de enero de 2015, el cual expone la dificultad en muchos ámbitos, de poder aunar los intereses de los diferentes sectores económicos afectados y de su plasmación en un texto general de aplicación, además de no ignorarse que algunos ámbitos del Derecho mercantil están sometidos, con mayor o menor intensidad, a una disciplina jurídico-pública, ha derivado en la exclusión de los contratos turísticos de dicho Texto legal, no esgrimiendo cuales han sido los argumentos básicos para ello, lo que a todas luces, es tremendamente desafortunado.

En efecto, pensamos que se debería haber mantenido, o al menos, regulado de forma unitaria, todos los contratos mercantiles-aquí incluimos al contrato de gestión hotelera- en aras a una generalización del Derecho mercantil.

A la vista de lo anterior, se ha desaprovechado la ocasión, no sólo en el contrato objeto de análisis, en particular, sino en los todos los contratos turísticos, en general, de 
darles una estructura legal y acompasada con la actividad económica de todos los actores que operan en el tráfico empresarial de este concreto sector, no sólo desde una perspectiva innovadora que se adaptara a las exigencias de una realidad palpable, sino también, dirigida en última instancia a una reordenación del sistema normativo.

En definitiva, volverán a ser nuevamente los operadores jurídicos -salvo nuevas propuestas legislativas- quienes deberán dar oportuna respuesta a las cuestiones que se circunscriban en torno a una relación contractual que ve incrementada, de forma notoria, su implantación, tanto nacional como internacional, dentro del nuevo escenario de la gestión turística actual.

\section{REFERENCIAS BIBLIOGRÁFICAS}

Alcover Garau, G. (2000). Aproximación al contrato de gestión hotelera. Revista de Derecho Mercantil, 237, 1104-1119.

Aurioles Martín, A. (Eds) (2003). Aspectos jurídico-mercantiles del turismo, Barcelona: Atelier, 45, 44-55.

Blanquer D. (Eds) (1998). Introducción al derecho administrativo, Valencia, 55, 49-87 Broseta Pont, M. y Martínez Sanz, F. (Eds) (2015). Manual de Derecho Mercantil, Madrid: Técnos, 75 .

Ceballos Martín, Mạ M., (Eds) (2002). Régimen jurídico de los establecimientos hoteleros, Madrid: Marcial Pons, 74.

Gallego Sánchez, E. (Eds). (2017). Derecho de la empresa y del mercado. Valencia: Tirant lo Blanch, 290, 290-291.

García Macho, R., Recalde Castells, A. y Petit Lavall, Mạ.V. Lecciones de derecho de turismo (Eds) (2000). Valencia: Tirant lo Blanch, 56.

Gómez Segade, A. (Eds). (1974). El know how. Concepto y prestación. Barcelona: Técnos, 45, 45-65.

Iñiguez Ortega, P. (Eds) (2015). El contrato de gestión hotelera. Valencia: Tirant lo Blanch, 52, 50-53.

Lázaro Sánchez, E.J. (1989). El desistimiento unilateral en los contratos de distribución: análisis de la Jurisprudencia al respecto. Revista la Ley, 1209, 1206-1215.

Martí Miravalls, J. (2008). El contrato de gérance-mandat: aproximación a los contratos de gestión empresarial. Revista Aranzadi de Derecho Patrimonial, 21, 3-5.

Martín Mateo, R., Martín Retortillo, S. y Villar Palasí, J.L. (1970) Aspectos jurídicoadministrativos del turismo en Actas del primer congreso italo-español de Profesores de Derecho Administrativo, Sevilla, 1966, Ministerio de Información y Turismo.

Martínez Cañellas, A. (2014). El contrato de gestión hotelera. Revista de Derecho de la UNED, 14, 829-861.

Martínez Sanz, F. (Eds.) (1995) La indemnización por clientela en los contratos de agencia y concesión, Civitas: Madrid, 24, 20-30.

Massaguer Fuentes, J. (1993). Los secretos industriales y comerciales y su transmisión: régimen jurídico. Derecho de la Propiedad Industrial. Jornadas sobre Derecho de la Propiedad Industrial. Madrid.

Montaner Montejano, J. (Eds). (1991). Estructura del mercado turístico, Síntesis, Madrid: Síntesis, 3, 3-15.

Peinado García, J.L. (Eds). (1996). El contrato de comisión: cooperación y conflicto, Consejo General de los Colegios Oficiales de Corredores de Comercio. Madrid: Civitas, 38. 
Pérez Moriones, A. (Eds). (1998). El contrato de gestión hotelera. Valencia: Tirant lo Blanch, 305, 303-307.

Pérez Guerra, R. y Ceballos Martín, M.M. (1996). A vueltas con el régimen jurídicoadministrativo de la distribución de competencias en materia de turismo y de otros títulos competenciales que inciden directamente sobre el mismo: el ejercicio de las competencias turísticas por la Comunidad Autónomas. Revista Andaluza de Derecho Administrativo, 27, julio-septiembre, 99.

Pérez Guerra, R. (2014). La intervención administrativa en el sector turístico español: la política turística. Revista Aragonesa de Administración Pública, 43-44.

Pérez Guerra, R. (2001). La intervención administrativa en la clasificación de los establecimientos hoteleros. Estudio comparativo del derecho turístico español. Revista Documentación Administrativa, 259, 259-260.

Prados Prados, S. (2008). Estudios sobre el derecho andaluz del turismo. Junta de Andalucía. Consejería de Turismo, Comercio y Deporte, 71, 67-72.

Roca Roca, E, Ceballos Martín, Ma M. y Pérez Guerra, R. (Eds) (1998). La regulación jurídica del Turismo en España. Almería: Universidad de Almería,

Robles Álvarez de Sotomayor, A. (1981). El derecho turístico. Estudios de Derecho mercantil en homenaje al profesor Antonio Polo: EDERSA, 921-927.

Tudela Aranda, J. (1996). Hacia un nuevo régimen jurídico del turismo: reciente legislación. Revista Aragonesa de Administración Pública, 45, 291-350. 